Revue d'histoire de l'enfance « irrégulière »

Le Temps de l'histoire

$3 \mid 2000$

L'enfant de justice pendant la guerre et l'immédiat après-guerre

\title{
Un enfant de la guerre devant le juge des enfants
}

Jean Mérat

\section{(2) OpenEdition}

Journals

Édition électronique

URL : http://journals.openedition.org/rhei/106

DOI : $10.4000 /$ rhei.106

ISBN : 978-2-7535-1640-3

ISSN : $1777-540 \mathrm{X}$

Éditeur

Presses universitaires de Rennes

Édition imprimée

Date de publication : 15 novembre 2000

Pagination : 107-108

ISSN : 1287-2431

Référence électronique

Jean Mérat, "Un enfant de la guerre devant le juge des enfants », Revue d'histoire de l'enfance "

irrégulière » [En ligne], 3 | 2000, mis en ligne le 11 juin 2004, consulté le 04 décembre 2020. URL

http://journals.openedition.org/rhei/106 ; DOI : https://doi.org/10.4000/rhei.106 


\section{Un enfant de la guerre devant le juge des enfants}

Jean Mérat ${ }^{(1)}$

Le 5 septembre 1945, un jeune de 17 ans était arrêté Porte de Clignancourt par les forces de l'ordre. Le même jour, ces dernières effectueront une perquisition dans un hôtel meublé. Dans la chambre du mineur, elles trouveront une feuille maladroitement rédigée. L'adolescent se raconte. ${ }^{(2)}$

"Élevé chez ma mère jusqu'à l'âge de 15 ans, je commençais ma vie d'aventure car, nous autres jeunes gens de 1941 à 1944, nous avons vécu une liberté autrement que tout autre jeune [...], un peu gangster, un peu voyou, plutôt zazou. " Pour Jean, ${ }^{(3)}$ la guerre fut, semble-t-il, un espace de liberté. En cet automne 1945, l'équilibre allait se rompre ; il se fait prendre place Pigalle, portant une valise pleine de vêtements. La police économique avait l'œil ; de nombreux jeunes se retrouvaient au poste suite au transport d'un bagage volumineux. Pendant l'interrogatoire, Jean affirmera avoir acheté les vêtements à un inconnu pour les revendre en "prélevant un petit bénéfice». Le système $\mathrm{D}$ fonctionnait toujours en cette fin d'année 1945.

En fait, les années d'occupation ne furent pas toujours faciles. A Savigny, centre d'observation du tribunal pour enfants du département de la Seine, le jeune se confie : "Pendant cette période, il n'y avait pas à manger, je ne gagnais pas beaucoup, javais toujours faim. " Jean, de nationalité italienne, vivait avec sa mère, femme de ménage, et son demi frère à Montreuil-sous-Bois. Il n'avait jamais connu son père. Il quitta l'école en 1941 à 14 ans sans son certificat d'études et fit un début d'apprentissage comme mécanicien. Puis vint le temps des petits boulots et sûrement de la faim.

Toujours sur la même feuille manuscrite, trouvée dans sa chambre, l'adolescent poursuit son récit. "Après 2 ans à peine de ce genre de vie coulante, je rentrais à partir de novembre 43 dans le fameux maquis, une vie de cow-boy... 3 mois de guerre, d'embuscades et de vie errante. "L'aventure
(1) Étudiant en histoire.

(2) AD Paris, 1418W51, Tribunal des enfants de Paris,

Cabinet $\mathrm{n}^{\circ} 2$.

(3) Nous avons changé le prénom du jeune.

Jean Mérat / pp. 107 à 108 
continuait pour lui, aventure qui le conduira à la prison du ChercheMidi et enfin dans un camp en Allemagne, d'où il sera libéré par les américains. Ainsi, lors de son arrestation en 1945, place Pigalle, il sera trouvé porteur d'une arme à feu. Il voulait retrouver celui qui avait dénoncé son groupe de résistants.

$\mathrm{Au}$ vu de ce qui précède, Jean donne le sentiment d'avoir senti le souffle de l'histoire. La feuille manuscrite était un synopsis pour " monter avec des amis un scénario $d u$ film de [sa] vie ». En attendant, le mineur vivait seul dans un hôtel meublé. De retour du camp, un médecin lui aurait conseillé de se reposer ; il ne travaillait donc pas, grâce à des allocations perçues au titre de déporté. Il vivotait avec, bien sûr, des petites combines qui le conduiront devant le juge des enfants.

Un psychiatre qui l'examine au centre de Savigny conclura :

"Il semble que ce soient les circonstances exceptionnelles, la vie du maquis et de déporté qui l'aient passagèrement déséquilibré. [...] [Jean] n'est ni un arriéré, ni un aliéné, ni un pervers. Il apparaît seulement comme passagèrement déséquilibré, exalté, hyperimaginatif. "

Le juge, le 14 décembre 1945, le confiera à la garde de sa mère, sous le régime de la liberté surveillée. 